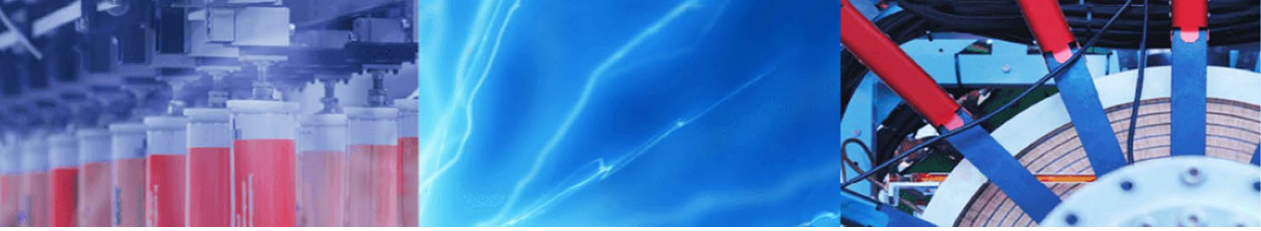

Research Article

\title{
Tailoring of stoichiometry and band-tail emission in PLD a-SiC thin films by varying He deposition pressure
}

\author{
Partha P. Dey ${ }^{1}$ (1) Alika Khare ${ }^{1}$
}

Received: 21 January 2020 / Accepted: 1 May 2020 / Published online: 11 May 2020

(c) Springer Nature Switzerland AG 2020

\begin{abstract}
The present work focuses on the effect of He pressure (vacuum, $10^{-2}-5 \mathrm{mbar}$ ) on structural and optical properties of amorphous silicon carbide (a-SiC) thin films, deposited by pulsed laser deposition (PLD) technique onto fused silica. A stoichiometric change occurs in PLD a-SiC film, with increasing He deposition pressure, transforming a near stoichiometric $\mathrm{SiC}$ material to C-rich $\mathrm{SiC}$ films till $1 \mathrm{mbar}$ of He pressure followed by drastic decrease in carbon (C) content at $5 \mathrm{mbar}$. The optical band gap of the films estimated using Tauc plot from UV-Vis-NIR transmittance spectra showed initial increase from 2.09 to $2.61 \mathrm{eV}$ with increasing He pressure from $10^{-6}$ to $1 \mathrm{mbar}$, then decrease to $2.11 \mathrm{eV}$ at $5 \mathrm{mbar}$. A broad band photoluminescence $(\mathrm{PL})$ peak featured in each of the a-SiC films at room temperature. The PL spectra exhibited blue shift in peak energy from 1.8 to $2.2 \mathrm{eV}$ with increase in atomic percentage of $\mathrm{C}$ from 49.4 to $62.4 \%$. The origin of the $\mathrm{PL}$ exhibited in these films is clearly due to band tail emissions from amorphous SiC structures which has been explained by the observed variation of PL intensity and corresponding FWHM with band gap as well as Urbach energy.
\end{abstract}

Keywords Thin film · Silicon carbide · Pulsed laser deposition · Optical properties · Photoluminescence

\section{Introduction}

$\mathrm{SiC}$ is another very useful Si-based material which is more robust than Si for microelectronics and optoelectronics devices. It possesses high breakdown field, excellent thermal conductivity, chemical inertness, high electron mobility, high thermal stability and mechanical hardness [1-3]. It exists in numerous polytypes, viz; cubic (C), hexagonal $(\mathrm{H})$ and rhombohedral (R). Among these polytypes, $3 \mathrm{C}-\mathrm{SiC}, 4 \mathrm{H}-\mathrm{SiC}$ and $6 \mathrm{H}-\mathrm{SiC}$ are the most important types which can be used for technological applications due to some superior physical, chemical, electronic and optical properties [4]. These polytypes of $\mathrm{SiC}$ have indirect wide band gap ranging from 2.7 to $3.3 \mathrm{eV}[1,5]$. This wide band gap gives it a very high breakdown field (about 10 times higher than that of Si or GaAs) [6]. It has optical phonons of high energy in the range of 100-120 meV [7] which leads to a high electron-saturation drift velocity of $2 \times 10^{7} \mathrm{~cm} / \mathrm{s}$ in $6 \mathrm{H}-\mathrm{SiC}[8]$, high acoustic velocity of $13,730 \mathrm{~ms}^{-1}$ [9] and a high thermal conductivity of $4.9 \mathrm{~W} / \mathrm{K} \mathrm{cm} \mathrm{[2].} \mathrm{It} \mathrm{posses}$ high temperature stability and is preferred over other semiconductor for radiation detectors under hazardous environment $[10,11]$. Due to strong bonding in $\mathrm{SiC}$, it is a very hard substance having Young's modulus around $400 \mathrm{GPa}$ [12] and hence can be used as tools for cutting and abrasion. Bulk SiC shows weak optical emission at room temperature on account of its indirect band gap. But nanostructured $\mathrm{SiC}$ due to quantum confinement effect (QCE) and its higher light-emission efficiency can have potential applications as emitters in blue and UV spectral range [13]. Band gap of nc-SiC can also be tuned by changing the size of the nanostructures. Luminescent $\mathrm{SiC}$

Electronic supplementary material The online version of this article (https://doi.org/10.1007/s42452-020-2865-2) contains supplementary material, which is available to authorized users.

Partha P. Dey, dey.partha@iitg.ac.in | 'Department of Physics, Indian Institute of Technology Guwahati, Guwahati, Assam 781039, India. 
films can be fabricated by incorporating various defects (dislocations, oxygen and hydrogen related defects and surface states) during the growth process [14]. The nc-SiC also exhibits greater elasticity and strength as compared to that of bulk SiC [15].

Another technologically useful low-cost $\mathrm{SiC}$ material is its amorphous form. Amorphous hydrogenated silicon carbide $\left(\mathrm{a}-\mathrm{Si}_{1-\mathrm{x}} \mathrm{C}_{\mathrm{x}}: \mathrm{H}\right)$ was first prepared by Anderson and Spear [16] by the glow discharge technique. Since then, amorphous $\mathrm{SiC}$ (a-SiC) films continued to be of considerable interest for both fundamental understanding as well as its technological utility in electronic and optoelectronics devices. The ratio of $\mathrm{Si}$ to carbon (C) as well as hybridization of $\mathrm{C}-\mathrm{C}$ bonds in the film is responsible in shaping up the structural, electrical and optical properties of the a-Si $i_{1-x} C_{x}$ films. The optical band gap and refractive index of the film are function of its carbon content ( $x$ ). By varying the carbon concentrations in $a-\mathrm{Si}_{1-x} \mathrm{C}_{x}$ the optical band gap can be tuned over a wide range (1.6-2.8 eV) [16]. This makes a-SiC thin films a potential candidate for applications in many kinds of optoelectronic devices with spectral tunability, such as tunable light-emitting diodes, image sensors, solar cells and wide spectral range photodetectors [17-21] The a-SiC thin films have been used as a protective coating for extreme UV optics due to its high reflectivity in this spectral region [22]. It can effectively be used as a thermally stable surface passivation material for highly efficient thin film silicon-based photovoltaic devices [23]. Furthermore, a-SiC films are chemically and mechanically stronger and more durable in terms of temperature resistance than a-Si films. As such, a-SiC films can be applied in silicon micromachining [3]. Amorphous $\mathrm{SiC}$ films have been prepared by the glow discharge technique [16], reactive sputtering [24], R.F. sputtering [25, 26], chemical vapor deposition (CVD) [27-29] and more recently via PLD [30-32]. The structural and electrical properties of these films depend on the deposition conditions. PLD offers the advantages of fabrication of stoichiometric as well as non-stoichiometric thin films in a single step by controlling the deposition parameters without the use of any hazardous gas. The laser wavelength, laser fluence, target-to-substrate distance, background ambient gas pressure and substrate temperature are the major parameters for shaping up the film properties fabricated via PLD process [33] thus providing wider flexibility to obtain the desired film quality.

The films grown by PLD in vacuum do not necessarily preserve the target stoichiometry [34]. Venkatesan et al. [35] and Gonzalo et al. [36] have demonstrated that the interaction of the ablated species in the Laser Produced Plasma (LPP) plume of the target material with a reactive or nonreactive background gas improves the morphology and could also modify the film stoichiometry. In PLD the LPP plume moves forward having a maximum particle density along the normal to the target. Moreover, the occurrence of different distributions of elements from multi-elemental target having different masses resulted in non-stoichiometric film deposition from multi-elemental target [37]. The laser fluence and background gas pressure controlling the collision driven plasma dynamics, plays a major role in determining the stoichiometry of the deposited film. A simple conjecture of these investigations was that the composition of films could be altered by introducing a background gas and controlling its pressure during the deposition process.

In the present paper, the fabrication of $\mathrm{SiC}$ thin films via PLD technique at $500{ }^{\circ} \mathrm{C}$ of substrate temperature under He pressure within the range of $10^{-6}-5 \mathrm{mbar}$ is reported. The structural properties of the films are characterized with Raman spectroscopy and stoichiometry using electron dispersive X-ray (EDX) spectroscopy. The optical properties of the films are studied by UV-Vis-NIR spectroscopy. The band gap of the films is estimated from Tauc plot. The room temperature $(\mathrm{RT})$ Photoluminescence $(\mathrm{PL})$ properties and their possible origin are also discussed.

\section{Experimental setup}

The SiC thin films were deposited on fused silica substrate via PLD at $500^{\circ} \mathrm{C}$ of substrate temperature for $30 \mathrm{~min}$ by ablating a SiC sputtering target using a pulsed Nd:YAG laser $(532 \mathrm{~nm}, 10 \mathrm{~ns}, 10 \mathrm{~Hz})$. The laser fluence was maintained at $\sim 6 \mathrm{~J} / \mathrm{cm}^{2}$. Films were fabricated under vacuum $\left(10^{-6} \mathrm{mbar}\right)$ and He ambient pressure of $10^{-2}, 10^{-1}, 1$ and 5 mbar. A micro-Raman setup (Jobin Vyon, Lab-Ram HR 800 ) was used in back scattering geometry to record the Raman spectra of the films. The Ar ion laser excitation of $488 \mathrm{~nm}$ wavelength was used for each measurement. The same set-up was employed to record the steadystate PL spectra at RT. Transmission electron microscopic (TEM) (JEOL-JEM 2010) images were recorded to observe any nanostructure formation within the films while the Selected Area Electron Diffraction (SAED) pattern were recorded for analyzing the crystalline nature of the films. The films were scratched out mechanically and transferred to Cu mesh grid for TEM imaging. The UV-Vis-NIR spectrometer (SHIMADZU UV-3101PC) was used for recording the transmittance spectra of the SiC films in order to estimate their optical band gaps using Tauc plot. The stylus profilometer (Veeco Dektak 150) was employed to measure the thickness of the films. Energy Dispersive X-ray (EDX) spectroscopy (Sigma, Zeiss) was employed for the study of film composition. 


\section{Result and discussions}

\subsection{Structural and compositional properties of a-SiC thin films}

The Raman spectroscopy of the SiC were conducted for analysing the structural properties of the films. Figure 1 exhibits the Raman spectra (with Y-offset) of a-SiC films fabricated at substrate temperature of $500{ }^{\circ} \mathrm{C}$ under vacuum $\left(10^{-6} \mathrm{mbar}\right)$ and He pressure ranging from $10^{-2}$ to $5 \mathrm{mbar}$. The figure shows three distinct broad bands in the regions of $200-700 \mathrm{~cm}^{-1}, 700-1200 \mathrm{~cm}^{-1}$ and $1300-1600 \mathrm{~cm}^{-1}$. The $200-600 \mathrm{~cm}^{-1}$ band is attributed to activation of Raman modes related to acoustic phonons of a-SiC $[27,38]$ or that of amorphous silicon (a-Si) [39] or their combination. The $3 \mathrm{C}-\mathrm{SiC}$ ( $\beta \mathrm{SiC} /$ cubic phase) exhibits the transverse optical (TO) and longitudinal (LO) optical Raman modes around $790 \mathrm{~cm}^{-1}$ and $960 \mathrm{~cm}^{-1}$ respectively [40]. The bands lying within $700-1100 \mathrm{~cm}^{-1}$ are much broad which indicates the presence of high structural disorder in $\mathrm{SiC}$ bonds and hence it is attributed to optical Raman modes of a-SiC. The third band $\left(1300-1600 \mathrm{~cm}^{-1}\right)$ is attributted to Raman modes resulting due to largely disordered $C-C$ bonds [41]. The intensity of $C-C$ peak w.r.t $\mathrm{Si}-\mathrm{Si} / \mathrm{Si}-\mathrm{C}$ (acoustic mode) peaks increased with increasing He pressure till 1 mbar followed by sudden disappearance of $\mathrm{C}-\mathrm{C}$ band in the film fabricated at $5 \mathrm{mbar}$ of $\mathrm{He}$ pressure. The deconvulation of Raman spectra for all the samples were done by fitting constituent multiple peaks with Gaussian lineshape function in order to extract the information, from the multiple peak features, regarding different bonding structures present within the SiC films.

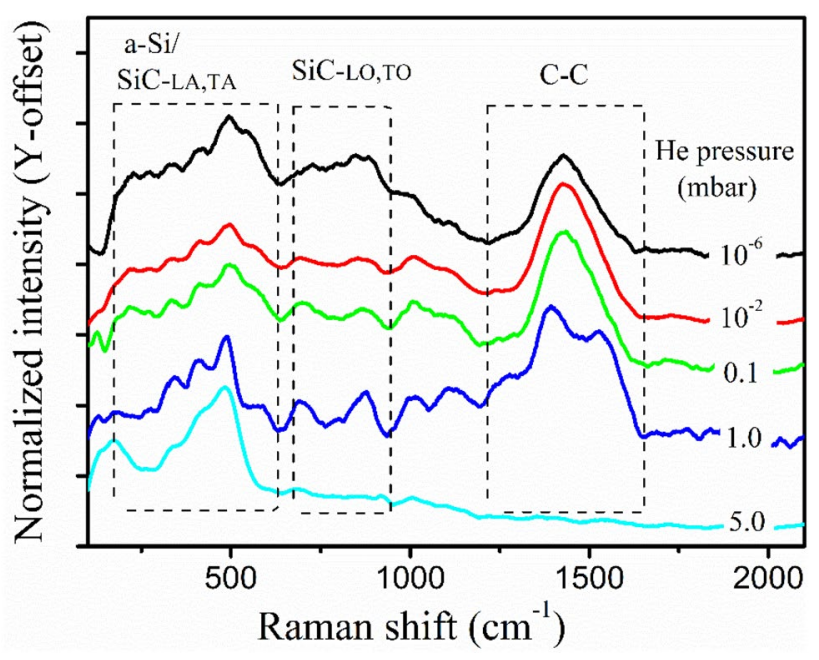

Fig. 1 Raman spectra of a-SiC thin films deposited at vacuum $\left(\sim 10^{-6} \mathrm{mbar}\right)$ and various He ambient pressure $\left(10^{-2}-5 \mathrm{mbar}\right)$
Figure 2a-e exhibit deconvulated Raman spectra of the films deposited under vacuum $\left(\sim 10^{-6}\right)$ along with those deposited under He pressure of $10^{-2}, 10^{-1}, 1$ and 5 mbar, respectively. The right hand side of respective figure contain the list of each peak position obtained from deconvolution. The peaks within broad bands in the regions of $200-700 \mathrm{~cm}^{-1}$ which corresponds to acoustic (LA and TA) Raman modes of a-SiC overlapped with Raman modes (TO, LO, LA and TA) of a-Si marked as region I [38, 39], while those within spectral region $700-1200 \mathrm{~cm}^{-1}$ corresponding optical Raman modes of a-SiC are marked as region II and peaks within $1300-1600 \mathrm{~cm}^{-1}$ corresponding to $\mathrm{C}-\mathrm{C}$ bonds are marked as region III. The third broadband region marked as III in the figures, is attributed to Raman modes arising from amorphous $C$ containing mixed phase of $s p^{3}-s p^{2}$ with random covalent network of tetrahedral-trigonal bonds characterised by distorted bond angles and bond lengths [41]. For the sample deposited under vacuum $\sim 10^{-6} \mathrm{mbar}$ (Fig. $2 \mathrm{a}$ ), all the prominent peaks were tabulated in Table 1, where peak corresponding to TO mode of a-Si at $498 \mathrm{~cm}^{-1}$ was most intense [42]. The peak positions and corresponding peak assignments of all the peaks from three spectral regions of SiC films are listed in Table 1.

The Raman spectra of SiC thin films deposited at higher He pressure (Fig. $2 b-e$ ), features similar peaks arising due to Raman active modes represented by I, II and III but with different relative peak intensities. Figure $2 f$ shows the plot of integrated peak intensities of Raman modes of a-SiC (acoustic) and a-Si $\left(\mathrm{I}_{\mathrm{SiC}, \mathrm{LA}+\mathrm{TA}} / \mathrm{I}_{\mathrm{a}-\mathrm{Si}}\right)$ representing region $\mathrm{I}$, of optical Raman modes of a-SiC ( $\left.\mathrm{I}_{\mathrm{SiC}, \mathrm{LO}+\mathrm{TO}}\right)$ for region II and that of Raman modes attributed to $\mathrm{C}-\mathrm{C}$ bonds $\left(\mathrm{I}_{\mathrm{C}-\mathrm{C}}\right)$ from region III w.r.t the total integrated Raman intensity as a function of deposition He pressure. A gradual decrease in the $I_{a-S i C, L A+T A}+I_{a-S i}$ from 0.4 to 0.31 , a slight decrease in $\mathrm{I}_{\mathrm{a}-\mathrm{SiC}, \mathrm{LO}+\mathrm{TO}}$ from 0.29 to 0.31 and increase in $\mathrm{I}_{\mathrm{C}-\mathrm{C}}$ from around 0.19 to 0.39 with increasing He pressure till 1 mbar was observed from this figure. But at $5 \mathrm{mbar}$ of He pressure, a drastic change in film stoichiometry was observed where $\mathrm{I}_{\mathrm{C}-\mathrm{C}}$ suddenly drops to 0.04 and $\mathrm{I}_{\mathrm{a}-\mathrm{SiC}, \mathrm{LA}+\mathrm{TA}}+\mathrm{I}_{\mathrm{a}-\mathrm{Si}}$ rises sharply to 0.67 while $I_{\mathrm{SiC}, \mathrm{OO}+\mathrm{TO}}$ decreases slightly. This rise in $\mathrm{C}-\mathrm{C}$ bonds relative to $\mathrm{Si}-\mathrm{Si}$ observed with the increase in He pressure up to $1 \mathrm{mbar}$ indicates a clear transition in stoichiometry of a-SiC films from a stoichiometric $\mathrm{SiC}$ material to $\mathrm{C}$-rich $\mathrm{SiC}$ but with further increase of He pressure resulted in formation of Si-rich $\mathrm{SiC}$ films. A lack of lighter elements occurs in films just in front of the multielemental target causing non-stoichiometric film deposition by PLD and this phenomenon is more evident at low fluences. This basically happens as the ablated elements with different masses exhibit different spatial distributions within LPP. Generally the lighter elements exhibit broader distributions while heavier species show 

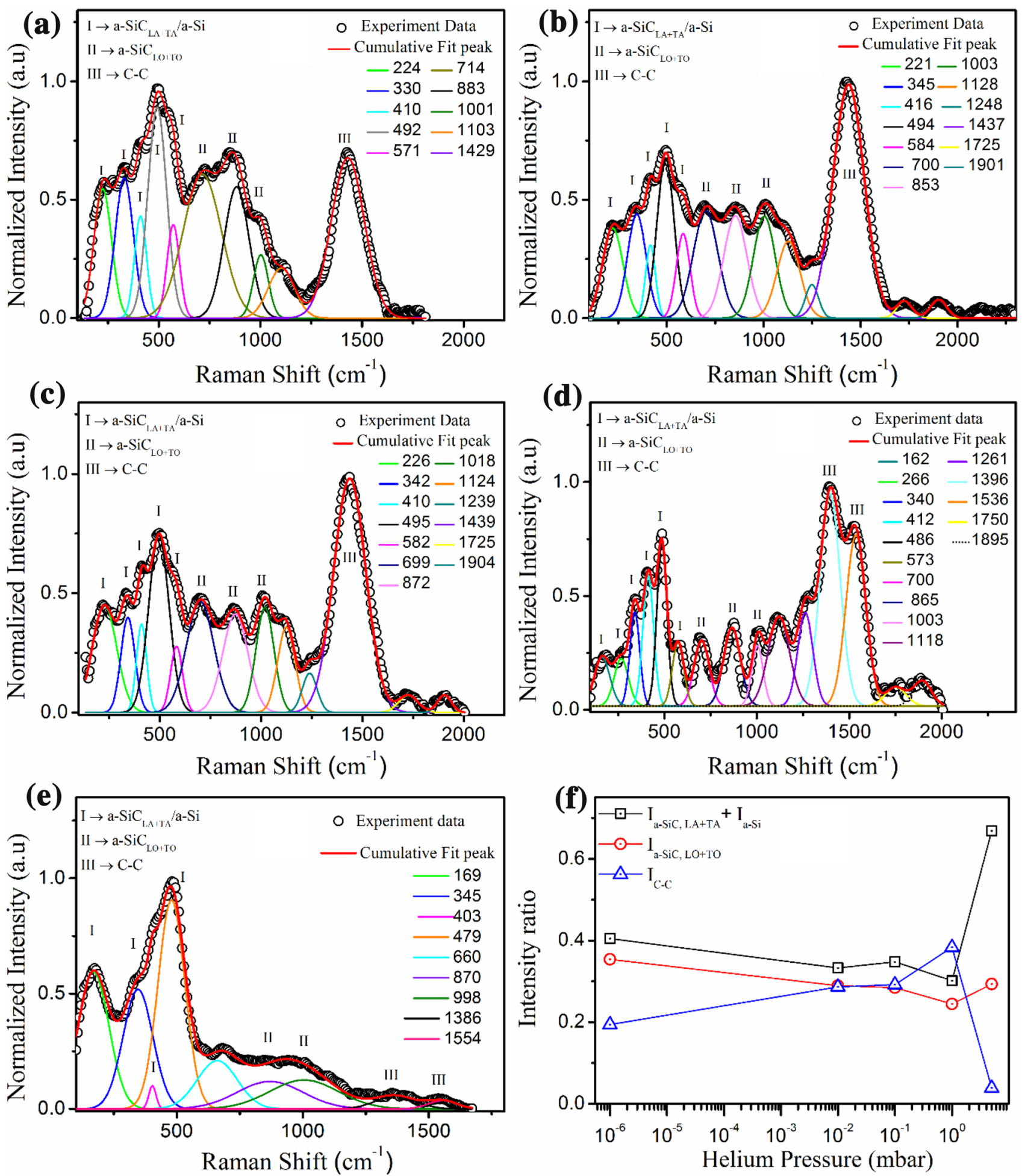

Fig. 2 De-convoluted Raman spectra of the a-SiC thin films at a vacuum $\sim 10^{-6}$ mbar and He pressure of b $10^{-2}, \mathbf{c ~} 10^{-1}, \mathbf{d} 1$ and e 5 mbar, respectively. The peak positions (in $\mathrm{cm}^{-1}$ ) are listed on right side (color coded) in the graphs. Figure $2 \mathrm{f}$ shows variation of nor-

malized integrated intensities of acoustic modes of a-SiC $\left(\mathrm{I}_{\mathrm{SiC}, \mathrm{LA}+\mathrm{TA}}\right)$ overlapped with Raman modes of a-SiC, optical modes of a-SiC $\left(\mathrm{I}_{\mathrm{SiC}, \mathrm{LO}+\mathrm{TO}}\right)$ and $\mathrm{C}-\mathrm{C}\left(\mathrm{I}_{\mathrm{C}-\mathrm{C}}\right)$ as a function of He pressure 
Table 1 List of peak positions in region I, II and III of Raman spectra of SiC films deposited under different He pressure

\begin{tabular}{llll}
\hline He pressure (mbar) & \multicolumn{2}{l}{ Peak positions $\left(\mathrm{cm}^{-1}\right)$ with peak assignments } \\
\cline { 2 - 4 } & Region I-I $I_{a-S i C, L A+T A}+I_{a-S i}$ & Region II-I $I_{\text {-SiC,LO+TO }}$ & Region III-I $_{C-C}$ \\
\hline $10^{-6}$ (vacuum) & $224,330,410,492,571$ & $714,883,1001$ & 1429 \\
$10^{-2}$ & $221,345,416,499,584$ & $700,853,1003$ & 1437 \\
$10^{-1}$ & $226,342,410,495,582$ & $699,872,1018$ & 1439 \\
1 & $266,340,412,486,573$ & $700,865,1003$ & 1396,1536 \\
5 & $169,345,403,479$ & 870,998 & 1386,1554 \\
\hline
\end{tabular}

narrower distributions due to collisions in LPP [37]. With increasing He pressure, the LPP was confined narrowing the spatial distribution of both Si and C toward the target normal and relative narrowing of spatial distribution was more prominent in lighter $C$ atoms resulting increase in $C$ atoms toward central region of plasma plume along target normal and hence incoming rate of $C$ onto the substrate increased resulting $C$ content increment in the deposited films with increasing He pressure till 1 mbar. But at 5 mbar the He pressure was too high causing over confinement of the plasma and thus restricting the incoming flux, where $C$ being lighter are more scattered away from target normal direction within the plume and hence $C$ deficient film was formed at that high pressure.

Figure 3 exhibits TEM images with inset providing corresponding SAED patterns of SiC films deposited under (a) vacuum and He pressure of (b) $10^{-3}$ and (c) $1 \mathrm{mbar}$. From TEM images of the SiC films the absence
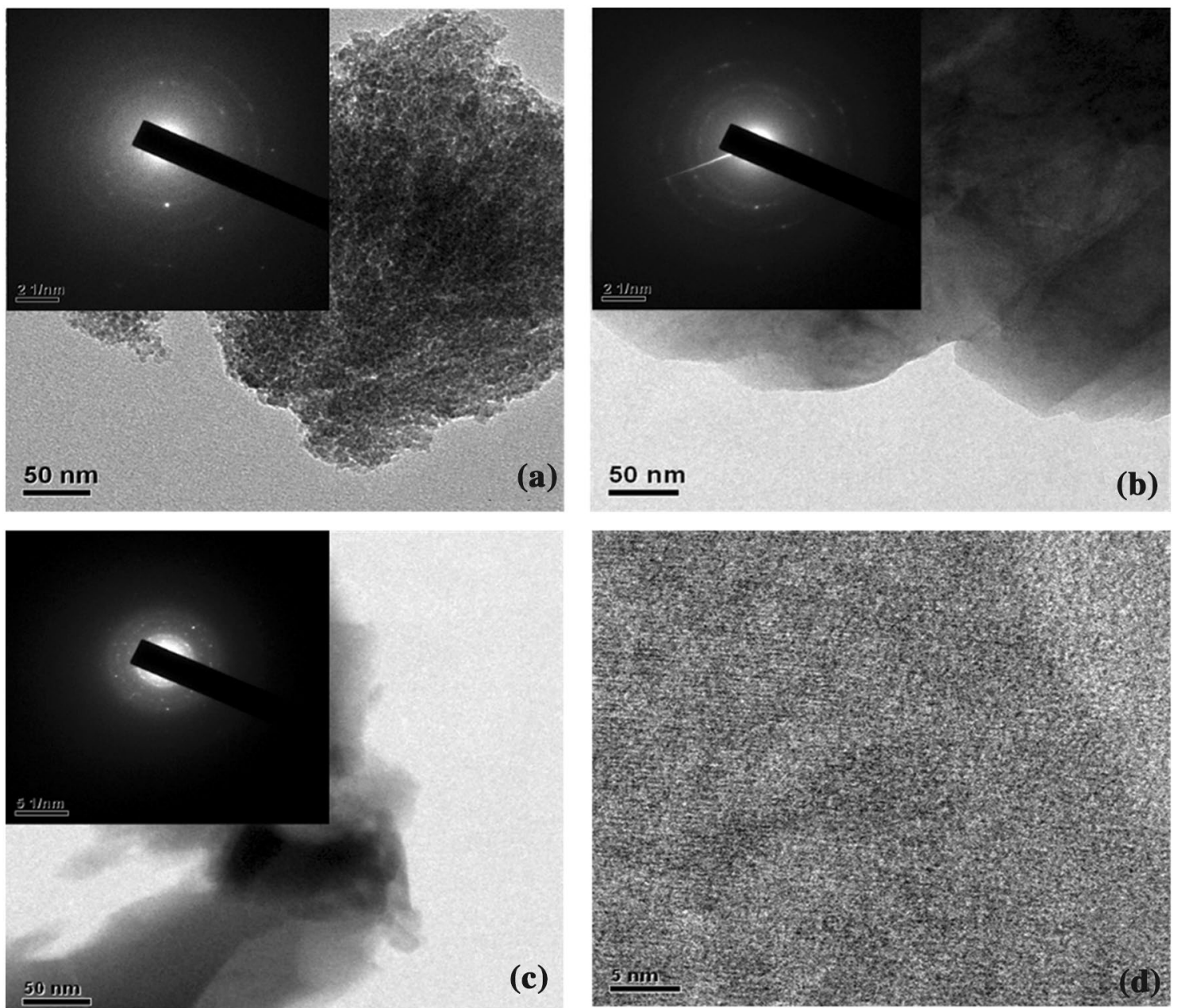

Fig. 3 TEM images with corresponding SAED patterns of SiC films deposited under a vacuum and He pressure of $\mathbf{b} 10^{-3}$ and $\mathbf{c} 1 \mathrm{mbar}$ while d exhibited its HRTEM image 

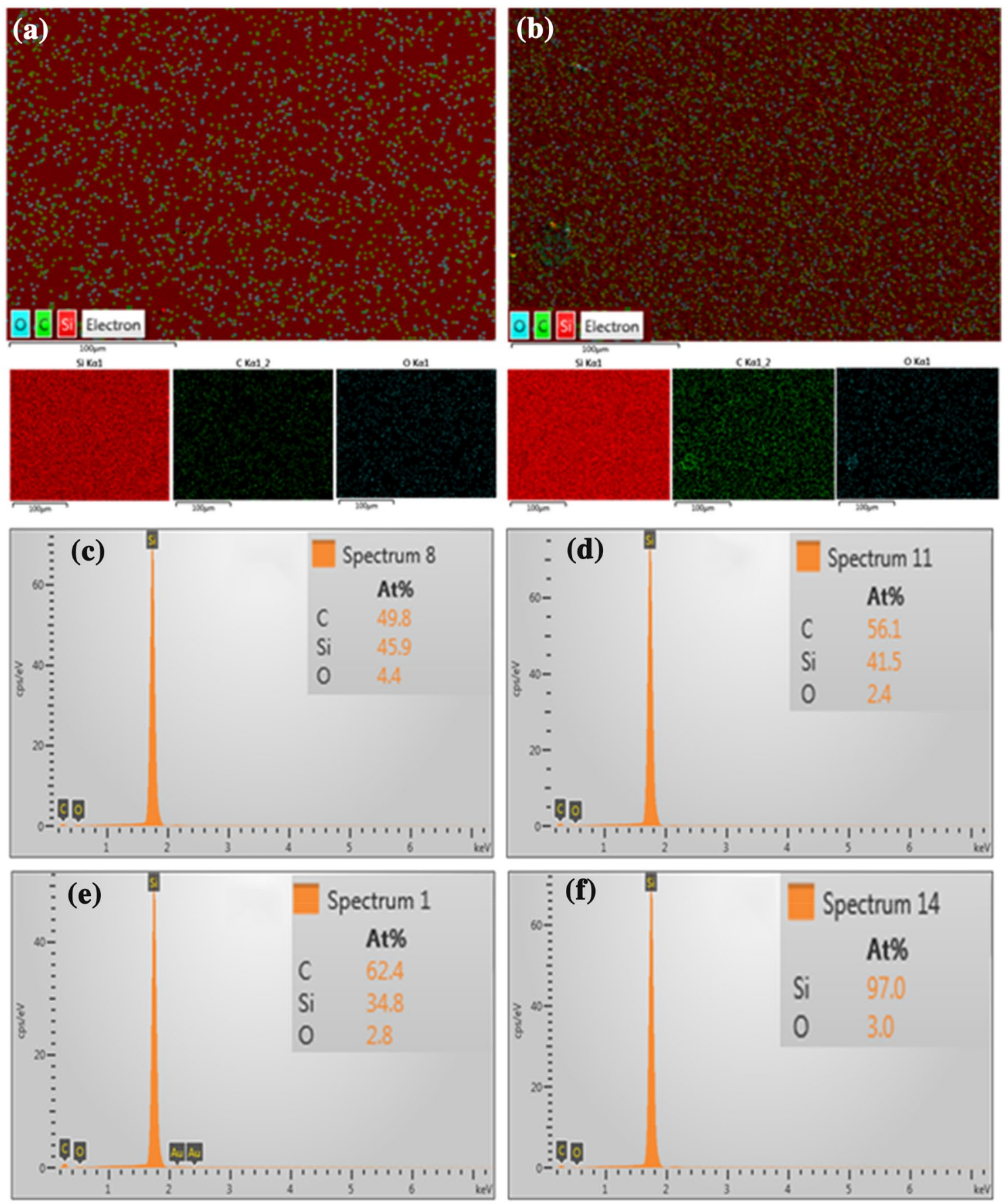

Fig. 4 EDX maps of a-SiC thin films fabricated at $\mathbf{a}$ vacuum and $\mathbf{b} 1 \mathrm{mbar}$ of He pressure. The EDX spectra for films deposited at $\mathbf{c}$ vacuum as well as under He pressure of $\mathbf{d} 10^{-1}$, e 1 and $\mathbf{f} 5$ mbar are also shown

of well-defined nanostructures within the films is evident. The SAED patterns exhibit diffused diffraction pattern with few bright diffraction spots at irregular places exhibiting largely amorphous nature of the SiC films. The presence of a few scattered bright diffraction spots might indicate presence of very few nanocrystals in comparison to overwhelming large proportion of amorphous matrix. Figure $3 \mathrm{~d}$ exhibited the HRTEM of the SiC films fabricated under 1 mbar of He pressure shows no features of well confirmed crystal planes nullifying the presence of any well-defined nanocrystals. The HRTEM images for other films also depicted similar results. Moreover, the claim for the films to be largely amorphous is also supported by the absence of diffraction peaks in $X$-ray diffraction spectra for all the films depicted in Fig. S1 (supplementary information).

\section{SN Applied Sciences}


Figure $4 a$, $b$ exhibit the elemental maps via EDX of SiC films fabricated at vacuum and $1 \mathrm{mbar}$ of He pressure, respectively. The EDX maps exhibit the presence of $\mathrm{Si}, \mathrm{C}$ and $O$ represented by red, green and cyan color, respectively, which are observed to be uniformly distributed over the film area indicating that the stoichiometry of the films is maintained throughout. The mono-elemental maps (depicted at the bottom of the Fig. 4a, b) corresponding $\mathrm{Si}, \mathrm{C}$ and $\mathrm{O}$ also show a homogenous distribution of these elements throughout the recorded area for both the films. The mono-elemental maps clearly show the increase in $\mathrm{C}$ (mapped as green color) for SiC films when deposition pressure was increased from vacuum level to $1 \mathrm{mbar}$ of He pressure. The EDX spectra of the films fabricated at vacuum as well as under He pressure of $10^{-1}, 1$ and $5 \mathrm{mbar}$ are shown in Fig. 4c-f, respectively. They exhibited presence of both $\mathrm{Si}$ and $\mathrm{C}$ atoms along with slight presence of atomic $\mathrm{O}<5 \%$ in all the films. The atomic $\%$ of $C$ within the films were $49.8,54.1,62.4$ and $0.0 \%$, corresponding to $x \sim 0.52,0.57,0.64$ and 0.0 in a- $\mathrm{Si}_{1-\mathrm{x}} \mathrm{C}_{\mathrm{x}}$ films fabricated under vacuum, $10^{-1}, 1$ and 5 mbar of He pressure, respectively. The $C \%$ in the film fabricated at 5 mbar could not be detected in EDX due to instrument's detectivity limit for carbon. Hence it is clearly evident that $\mathrm{C} \%$ increased from 49 to $62 \%$ with increasing He pressure till 1 mbar resulting C-rich a-SiC films and thereafter it drops drastically at 5 mbar forming Si-rich a-SiC films which also supports the Raman results (Fig. 2f).

\subsection{Optical properties of PLD a-SiC thin films}

Figure $5 \mathrm{a}$ exhibits the transmission spectra of all the a-SiC films, from which the absorption coefficient (a) of all the films was estimated using the relation, derived from BeerLambert law [43]:

$\alpha(v)=-\frac{\ln (T)}{d}$

where $T$ is the transmittance and $d$ is the film thickness. The film thickness measured by surface profilometer for the a-SiC films fabricated under vacuum as well as He pressure of $10^{-2}, 10^{-1}, 1$ and 5 mbar were found to be 280 , $275,390,304$ and $210 \mathrm{~nm}$, respectively. The thickness of the films increased initially with increasing He pressure till $10^{-1}$ mbar which is caused by the increase of the particle flux due to the spatial confinement of LPP resulting higher deposition rates and hence thickness increases. But beyond $10^{-1} \mathrm{mbar}$, high pressure caused over confinement of the plasma and the incoming flux were obstructed while approaching the substrate resulting in gradual reduction in film thickness from 390 to $210 \mathrm{~nm}$ with further increase in He pressure from $10^{-1}$ to $5 \mathrm{mbar}$. The relation between absorption coefficient $(a)$ and band gap energy for amorphous semiconductors is as follows [44],

$(\alpha h v)^{\frac{1}{2}}=B\left(h v-E_{g}\right)$

where $B$ is a constant, $h v$ is photon energy and $E_{g}$ is optical bandgap. The Tauc plot, (ahv) $)^{1 / 2}$ versus $h v$ for all the films is shown in Fig. 5b. The optical band gap $\left(E_{g}\right)$ was measured from the intercepts (extrapolations) of the linear region of the plots on the $h v$ axis and is shown in the inset of Fig. 5b. The band gap of SiC thin films deposited under vacuum was found to be $2.09 \mathrm{eV}$ and it increases gradually to $2.68 \mathrm{eV}$ with increasing He pressure up to 1 mbar but beyond this it reduces to $2.11 \mathrm{eV}$ with further increase in He pressure to 5 mbar. The fraction of Si and C defining
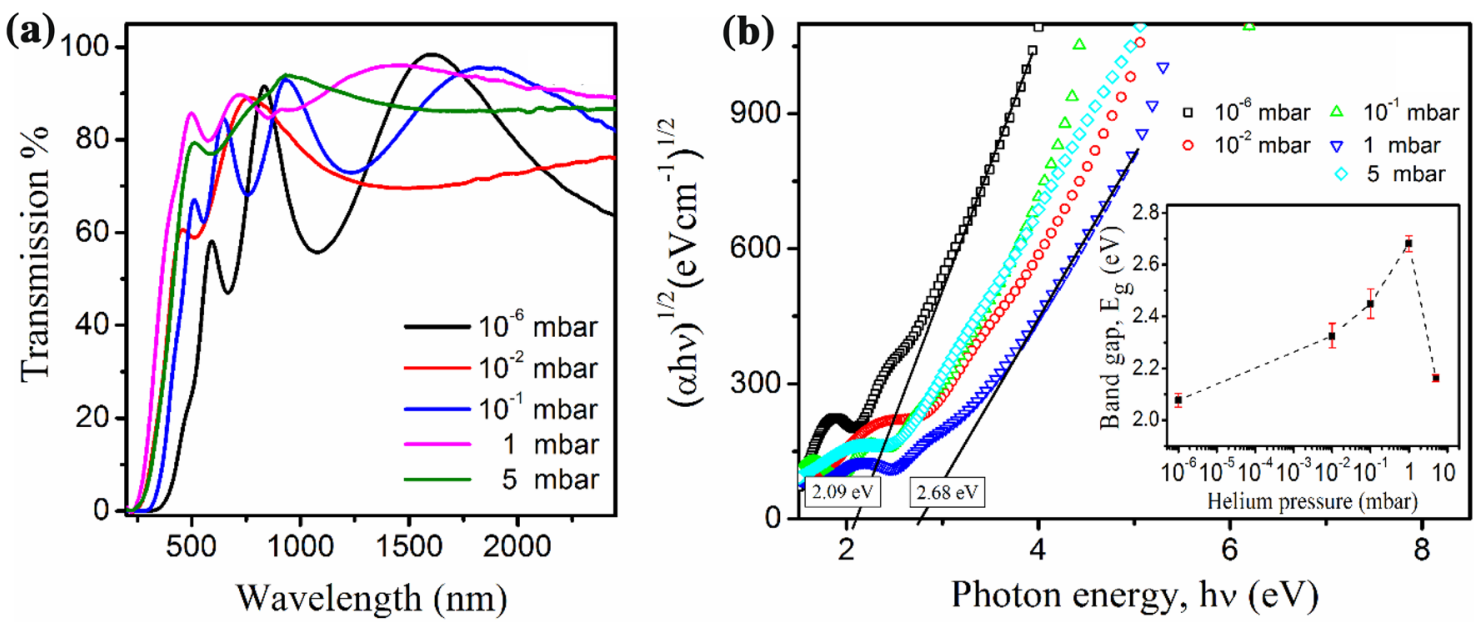

Fig. 5 a Transmission spectra and $\mathbf{b}$ Tauc plot with inset showing the band gap of a-SiC thin films deposited under different ambient pressure of $\mathrm{He}$ 
the film stoichiometry and bonding configurations for the carbon atoms are the determining factor for shaping up the optical band gap of the $a-\mathrm{Si}_{1-x} \mathrm{C}_{x}$ films. The band gap of $a-\mathrm{Si}_{1-x} \mathrm{C}_{x}$ films do not follow a monotonic increase with $x$ but in all cases exhibit a maximum at $x=x_{c} \sim 0.65$ due to the trivalent $\left(s p^{2}\right)$ and tetravalent $\left(s p^{3}\right)$ forms of carbon [45]. Robertson explained this non-monotonic behavior of the band gap energy with $x$ for the first time [46], where he showed that below $x_{c}$ the band edge shows $\sigma$-bonded $\mathrm{Si}-\mathrm{C}$ $s p^{3}$ character (high band gap), whereas above $x_{c}$ it exhibits $\pi$-bonded $C=C s p^{2}$ like character (low band gap). With increase in deposition He pressure from vacuum to $1 \mathrm{mbar}$, an increase of optical band gap of films from $2.09 \mathrm{eV}$ to a maximum of $2.68 \mathrm{eV}$ was observed due to the increases in the $C$ content within the films as evident from Raman results, Fig. $2 \mathrm{f}$, as well as EDX results exhibiting rise in $x$ from 0.52 to 0.64 nearing $x_{c} \sim 0.65$. But beyond this point band gap reduces to $2.11 \mathrm{eV}$ for films deposited at $5 \mathrm{mbar}$ of He pressure as C-content declines drastically to nearly $25 \%$ resulting the formation of Si-rich SiC films.

PL spectra of PLD SiC films fabricated under vacuum and $10^{-2}-5$ mbar of He ambient pressure were presented in Fig. 6. The PL spectra of all these a-SiC films exhibited PL having multi-peak features and broad band nature within visible spectral range. The PL peak intensity increased with increasing pressure till a maximum of 1 mbar then it decreased at 5 mbar of He pressure. With increasing $\mathrm{He}$ pressure till 1 mbar a blue-shift in PL peak energy was observed and thereafter film fabricated at 5 mbar exhibited a red shift in PL peak energy.

To get a clear picture, the de-convoluted PL spectra of the films deposited under vacuum $\left(10^{-6}\right)$ as well as He pressure of $10^{-2}-5$ mbar were shown in Fig. $7 a-e$, respectively. The peaks were fitted with multiple Gaussian lineshape functions. All these PL spectra showed two

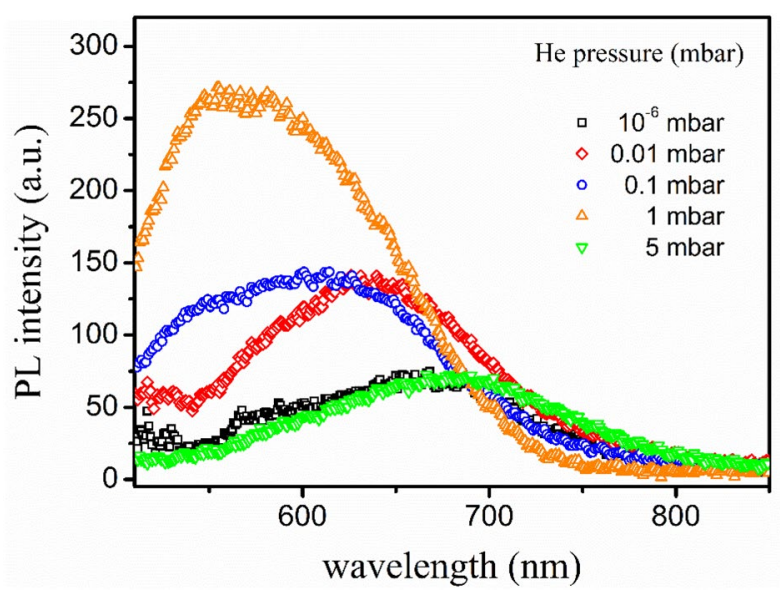

Fig. 6 RT PL spectra of a-SiC thin films deposited under vacuum ( $\left.10^{-6} \mathrm{mbar}\right)$ and different He pressure $\left(10^{-2}-5 \mathrm{mbar}\right)$ peaks, at low photon energy within the range of $1.4-2 \mathrm{eV}$ and second one toward higher photon energy ranging from 1.6 to $2.4 \mathrm{eV}$. The peak positions are depicted in the respective figures. Figure $7 f$ shows the variation of $E_{g^{\prime}} \mathrm{PL}$ peak energies $\left(E_{P L}\right)$, both for high intensity, $\mathrm{P}(\mathrm{H})$, as well for low intensity peak, $\mathrm{P}(\mathrm{L})$, and the integrated $\mathrm{PL}$ intensity of $\mathrm{P}(\mathrm{H})$ of the $\mathrm{SiC}$ films as a function of deposition $\mathrm{He}$ pressure. An increase in peak energy of $\mathrm{P}(\mathrm{H})$ from 1.83 to $2.21 \mathrm{eV}$ is observed along with increase in the band gap of the films from 2.09 to $2.68 \mathrm{eV}$ with increasing deposition He pressure up to $1 \mathrm{mbar}$. At He pressure of $5 \mathrm{mbar}$ as $E_{g}$ reduces to $2.1 \mathrm{eV}$ and the peak position of $\mathrm{P}(\mathrm{H})$ also reduced to $1.81 \mathrm{eV}$. In the $\alpha-\mathrm{SiC}$ films, there could be three main mechanisms governing the PL emission: emissions via defect states [14, 47], QCE induced emission [48-50], and band tail state emission [51-53]. For defect-related PL, the peak position remains fixed at a certain wavelength, in contrast a blue shift in PL energy with increasing band gap is observed here. For a QCE-induced PL, blue shift of peak position occurs with increasing band gap due to decrease in size of the nanocrystals and PL peak energy is close to band gap energy. But in present case though PL peak of the films exhibited blue shift with increasing $C$ content, but the PL peak energy were much lower than band gaps of corresponding films confirming no bandedge emissions due to QCE of nanocrystals. Moreover, the possible origin due to QCE was ruled out because of the absence of adequate nanocrystals of the order of exitonic Bohr diameter of $\mathrm{Si} / \mathrm{SiC}(\sim 9 / 5 \mathrm{~nm})$ or smaller as confirmed by the TEM studies (Fig. 3).

The $E_{\mathrm{PL}}$ is seen to increase from 1.83 to $2.21 \mathrm{eV}$ with increasing $E_{g^{\prime}}$ corresponding to red to green emission. The PL peak position $\left(E_{P L}\right)$ of $\mathrm{P}(\mathrm{H})$ as a function of optical band gap energy, shown in Fig. 8, follows a linear relation with a slope of 0.66 and an intercept of $0.41 \mathrm{eV}$ (linear regression $R=0.975$ ) [54]. Similar linear relations were also reported by Wakita et al. [55] $\left(E_{P L}=0.37 E_{g}+0.87 \mathrm{eV}\right)$ and Wang et al. [56] $\left(E_{P L}=0.35 E_{g}+1.12 \mathrm{eV}\right)$ for amorphous $\mathrm{SiN}_{\mathrm{x}}$ films, supporting that the optical transitions involve the band tail states. The $E_{P L}$ was much lower than $E_{g}$ $\left(E_{g}-E_{P L} \sim 0.3-0.4 \mathrm{eV}\right)$ and could be attributed to recombination of photo-generated electron-hole pairs after thermalization within localized band tail states [57].

However, in the present work, the observed difference in $E_{\mathrm{PL}}$ and $E_{g}$ is believed to be associated with the tail-to-tail states recombination, based on a model that has been generally accepted for PL in amorphous semiconductors such as $a-\mathrm{Si}: \mathrm{H}, \mathrm{a}-\mathrm{SiN}_{\mathrm{x}}$ and $a-\mathrm{Si}_{1-\mathrm{x}} \mathrm{C}_{\mathrm{x}}: \mathrm{H}$ [54, $56,58]$. In this model, electrons and holes, for example within a-Si system, are first excited to higher energy states via photo-excitation as shown in Fig. 9a, and then due to thermalization processes, the photon-generated carriers relax to the deepest states of the band tails of 

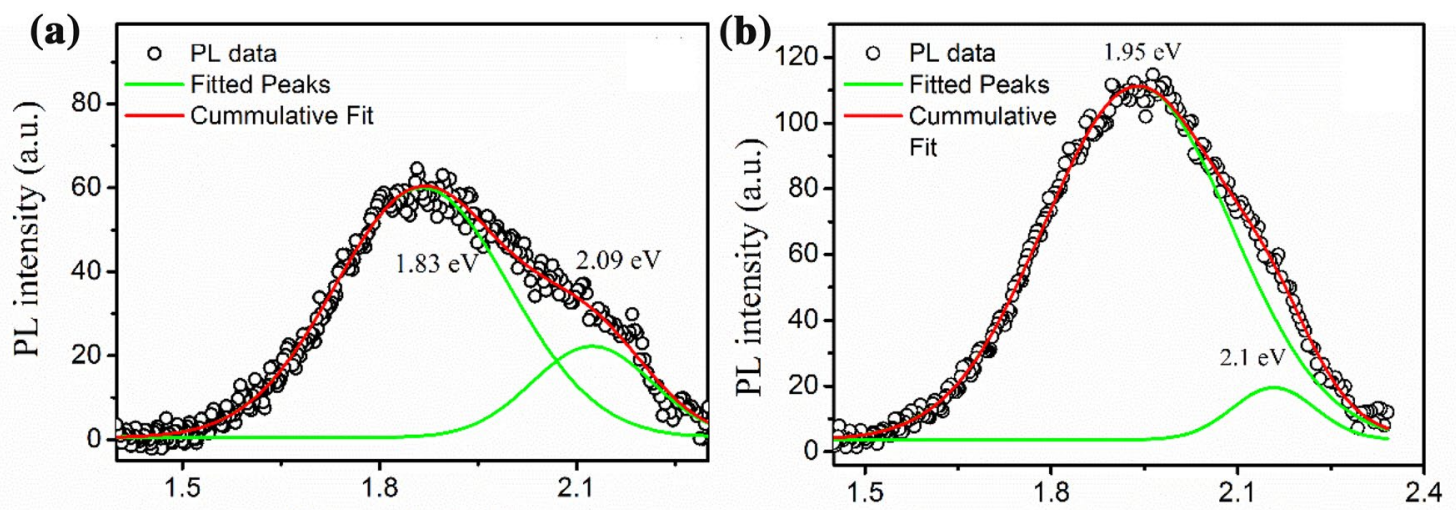

(c)

Energy, hv (eV)

(d)
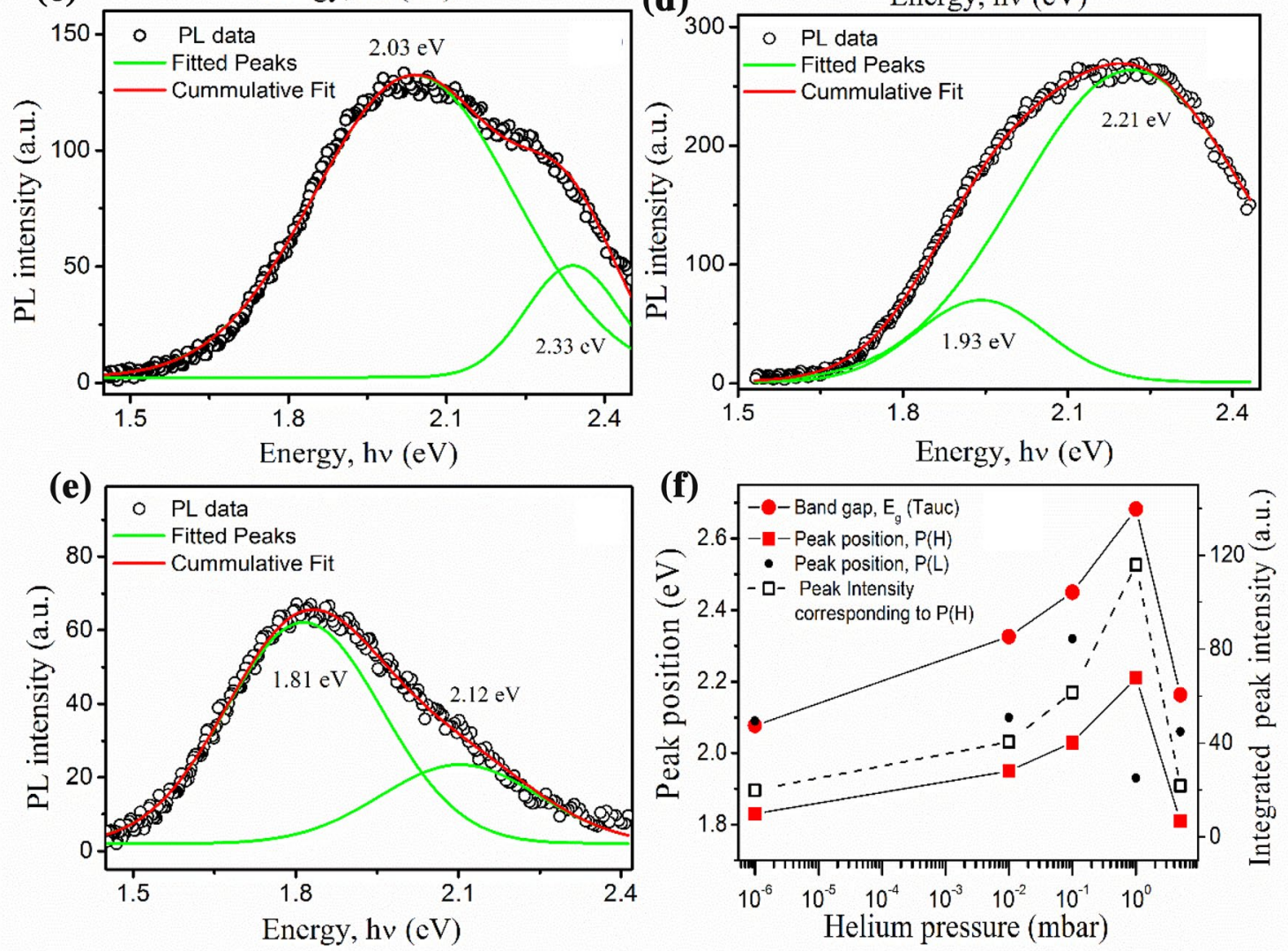

Fig. 7 De-convoluted PL spectra of a-SiC thin films deposited a under vacuum as well as under He pressure of $\mathbf{b} 10^{-2}, \mathbf{c} 10^{-1}, \mathbf{d}$ 1 , e 5 mbar, respectively. Figure $7 f$ depicts plot of band gap, peal

positions of high intensity peak, $\mathrm{P}(\mathrm{H})$ and low intensity peaks, $\mathrm{P}(\mathrm{L})$ along with corresponding peak intensity of $\mathrm{P}(\mathrm{H})$ as a function of $\mathrm{He}$ pressure

conduction band in absence of any thermal excitation of system (say at absolute zero temperature). Finally, the radiative recombination occurs from these low lying energy states of the band tails exhibiting PL. For amorphous materials, RT PL intensity has been observed to be a function of competition between radiative recombination mediated by tail-to-tail transitions and nonradiative process like thermal quenching. With increasing temperature the carriers are thermally excited which can easily bring photon-generated carriers from the

localized band tail state to the extended state through which the carriers eventually recombine via non-radiative processes resulting quenching of the $\mathrm{PL}[54,59]$. At RT, PL in a-Si is reported to be quenched fully arising due to thermal excitation of localized states as schematically depicted in Fig. 9b. But with addition of carbon in the a-Si matrix more structural disorders are developed and consequently deeper states (longer band tails) are formed resulting increase in the activation energy (energy required to lift electrons from the localized 


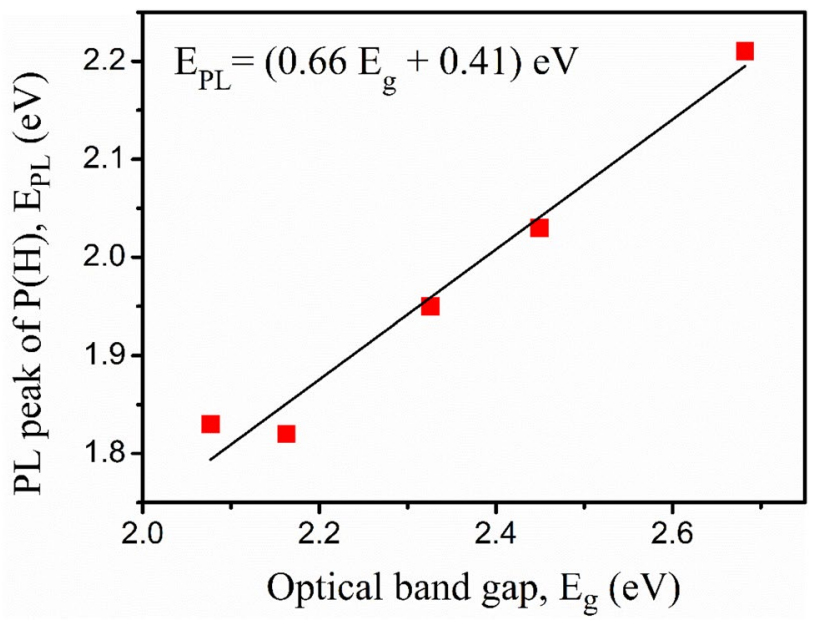

Fig. 8 Plot of PL peak energy $E_{P L}$ versus optical band gap $E_{g}$ (Tauc gap) of a-SiC thin films

band tail state to the extended state) of the carrier in the band tail region. This results in suppression of thermal quenching and large number of carriers still exists within the localized states which are readily available for radiative recombination resulting intense $\mathrm{PL}$ from a-SiC even at RT, as depicted in Fig. 9c.The intensity of the PL and its FWHM depends critically on the band-tail width and the density of the band tail states which are usually controlled by microstructures of the films.
Figure 10a shows the plot of In a versus $h v$ for the SiC films deposited under various He pressures. The Urbach energy $\left(E_{U}\right)$ of these films was estimated from the slope of these plots. Figure $10 \mathrm{~b}$ shows the variation of $E_{U}$ and the energy difference between band gap energy and PL emission $\left(E_{g}-E_{P L}\right)$ of a-SiC films as a function of He pressure. From this figure, the increase of $E_{U}$ from 0.78 to $0.96 \mathrm{eV}$ with increasing He pressure from $10^{-6}$ to 1 mbar was observed followed by abrupt falls to $0.82 \mathrm{eV}$ at $5 \mathrm{mbar}$ of He pressure. As the $I_{C-C}($ Raman results, Fig. 2f) and atomic $\%$ of $C$ atoms (EDX results, Fig. $4 c-f$ ) also follows similar trend with increasing He pressure hence increase in $E_{U}$ can be considered to be increasing in proportional to $C$ content in the SiC films. In the presence of excessive carbon atoms the structural disorder in the film increases owing to changes in bond lengths and bond strengths of Si and $C$ bond while producing deeper states depicted by larger $E_{U}$. Now, $E_{g}-E_{P L}$ of a-SiC thin films shows similar trend as that of $E_{U}$ as a function of He pressure inferring that $E_{U}$ and $E_{g}-E_{P L}$ holds a linear relationship. The plot of $\left(E_{g}-E_{P L}\right)$ as a function of He pressure (Fig. 10b) actually depicts its increase with increasing $C$ content. The reason for this is that as the $C$ content in the films increases band tails widens ( larger $\left.E_{U}\right)$ resulting creation of deeper states. Now, as the tail-to-tail radiative transition takes place from deepest possible energy states after thermalization, the gap between $E_{g}$ and $E_{P L}$ increases [56].

Figure 11 shows the variation of values of FWHM and integrated intensity of the most intense PL peak, $\mathrm{P}(\mathrm{H})$
Fig. 9 Schematic of photogeneration of e-h pair and PL mechanism in amorphous semiconductors

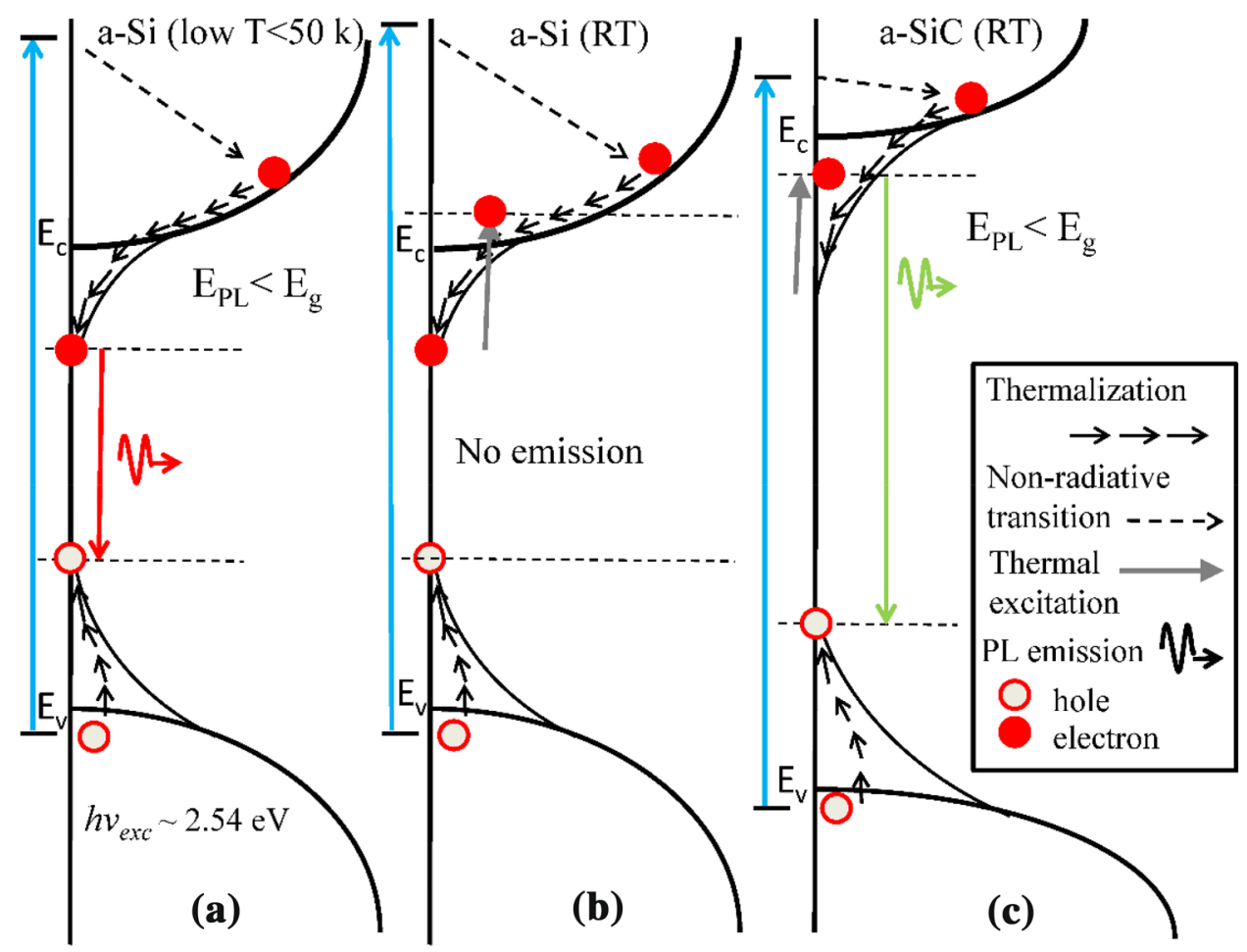



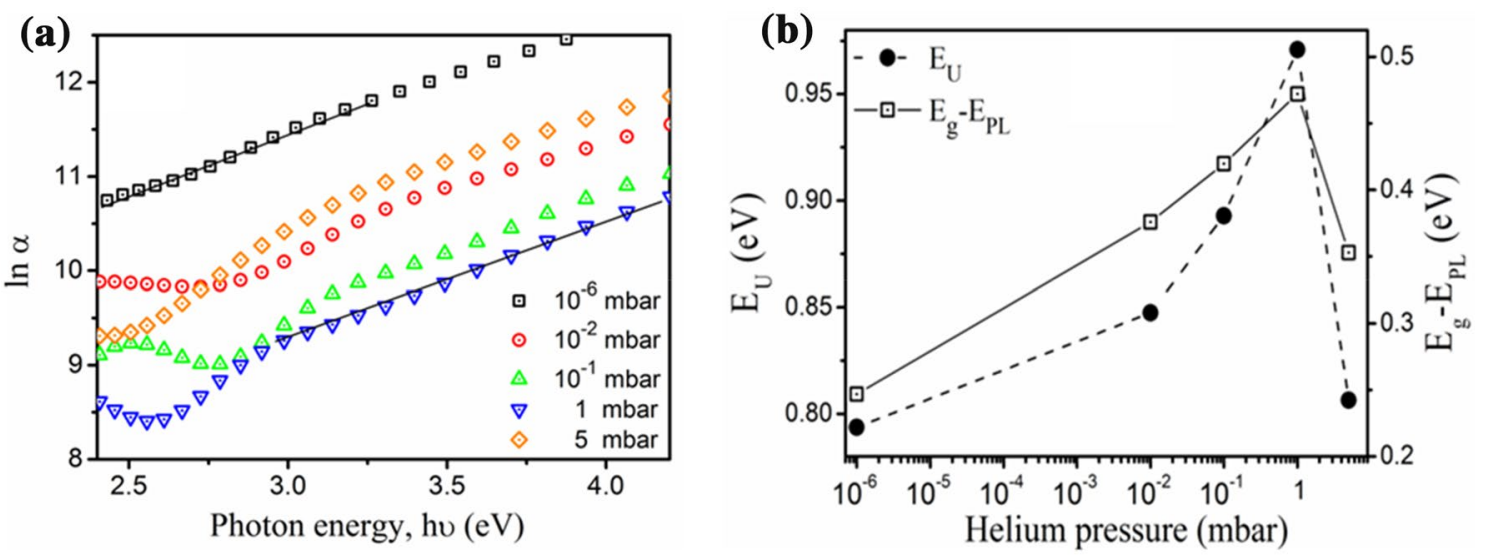

Fig. 10 a Plot of In a versus $h v$ and $\mathbf{b}$ variations of $E_{U}$ and $E_{g}-E_{P L}$ of a-SiC thin films as a function of He pressure from $10^{-6}$ to $5 \mathrm{mbar}$

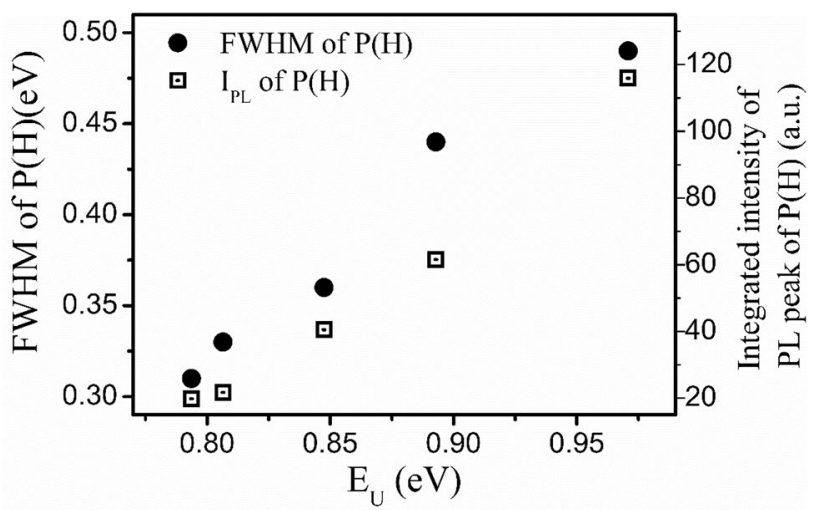

Fig. 11 Variation of FWHM and integrated intensity of the most prominent and intense $\mathrm{PL}$ peak, $\mathrm{P}(\mathrm{H})$, as a function of Urbach energy $\left(E_{U}\right)$ of the a-SiC thin films

with the Urbach energy, $E_{U}$. It can be seen that both these parameters increase almost linearly with $E_{U}$. This linear relationship between the FWHM of the PL band and the Urbach energy observed in this work can be explained by the models reported for band tail emissions in a- $\mathrm{Si}_{1-x} \mathrm{C}_{x}: \mathrm{H}$ [54] and a-SiN $\mathrm{N}_{x}: \mathrm{H}$ films [56], where the main factor that contributes to the bandwidth of PL band is the structural disorder induced band tail widening. The linear increase of intensity of PL peak, $\mathrm{P}(\mathrm{H})$, as a function of $\mathrm{E}_{\mathrm{U}}$ as shown in Fig. 11 can be understood by considering the widening of band tail introduced by addition of $\mathrm{C}$ atoms in $\mathrm{SiC}$ structure. With the increase in carbon content in the SiC films, more structural disorder were formed and consequently deeper states were produced which elevates the activation energy (difference between the low lying localized states and extended states) required for thermal quenching of the carriers. The transition of photo-generated carriers from the localized states of band tail to the extended state has been inhibited by the increase in activation energy resulting in sharp decline in thermal quenching and consequently, PL peak intensity increased in a-SiC with higher $C$ content. $[52,54]$ The $a$-SiC prepared by the PLD technique could be a promising material for applications in LEDs and large area displays as these films displays PL ranging from red to green spectral region.

\section{Conclusions}

The present work deals with how the structure and optical properties of PLD a-SiC films evolves under deposition condition of vacuum $\left(10^{-6} \mathrm{mbar}\right)$ and in presence of He gas pressure from $10^{-2}$ to 5 mbar. Raman spectra of the $\mathrm{SiC}$ films depicts amorphous nature of the films and exhibits the rise in $\mathrm{C}-\mathrm{C}$ bonds relative to $\mathrm{Si}-\mathrm{Si}$ bonds. This infers a stoichiometric transition of a-SiC films from stoichiometric to $\mathrm{C}$-rich $\mathrm{SiC}$ as He pressure rises till $1 \mathrm{mbar}$ beyond which $\mathrm{SiC}$ films became $\mathrm{Si}$-rich at $5 \mathrm{mbar}$ pressure of $\mathrm{He}$. This transition has been explained on the basis of how the stoichimetry of film was effected by the dynamics of differently massive ablated ions from multielemental target under different inert gas pressure. The amorphous nature of the films was also confirmed by TEM results. The band gap of a-SiC thin films exhibited a blue shift from 2.09 to $2.68 \mathrm{eV}$ with increasing $\mathrm{C}$ content from 49.8 to $62.8 \%$ resulting from stoichiometry transition in the films as a function of He pressure. The a-SiC thin films showed a broad band PL whose peak position behaves similarly to the band gap of the films as a function of He pressure. The $E_{P L}$ was much lower than $E_{g}$ and the observed shift in $E_{\mathrm{PL}}$ w.r.t $E_{g}$ is believed to be associated with the band-tail recombination between localized states observed in most of the amorphous semiconductors. The observed linear relationship between the FWHM of the PL band and the Urbach energy suggest 
that the band tail widening is the major factor contributing to the observed wide bandwidth of PL peaks. The rise in PL intensity of the a-SiC films observed with increasing $\mathrm{C}$-content was resulting from the decline in thermal quenching promoted by creation of deeper states with incorporation of more $\mathrm{C}$ atoms. The novelty of the present work lies in the fabrication of a-SiC films of variable stoichiometry via PLD just by increasing He gas pressure during deposition, which has also resulted in stoichiometry controlled tunable photoluminescence peaking from far red to green region.

Acknowledgements The authors acknowledge CIF, IIT Guwahati, Guwahati for providing the Laser micro Raman and EDX facilities. The work was partially supported by DRDO, India (Grant No. ERIP/ ER/07003/30/M/01/1138).

\section{Compliance with ethical standards}

Conflict of interest The authors declare that they have no known conflict of interest that could have influence the work reported in this paper.

\section{References}

1. Morkoç H, Strite S, Gao GB, Lin ME, Sverdlov B, Burns M (1994) Large-band-gap SiC, III-V nitride, and II-VI ZnSe-based semiconductor device technologies. J Appl Phys 76:1363-1398

2. Slack GA (1964) Thermal conductivity of pure and impure silicon, silicon carbide, and diamond. J Appl Phys 35:3460-3466

3. Klumpp A, Schaber U, Offereins $H L$, Kühl K, Sandmaier $H$ (1994) Amorphous silicon carbide and its application in silicon micromachining. Sens Actuators A 41:310-316

4. Saddow SE, Agarwal A (2004) Advances in silicon carbide processing and applications. Artech House, Norwood

5. Harris GL (1995) Properties of silicon carbide. INSPEC-the Institution of Electrical Engineers, London

6. Muench WV, Pfaffeneder I (1977) Breakdown field in vaporgrown silicon carbide $p-n$ junctions. J Appl Phys 48:4831-4833

7. Feldman DW, Parker JH, Choyke WJ, Patrick L (1968) Phonon dispersion curves by Raman scattering in $\mathrm{SiC}$, Polytypes $3 \mathrm{C}, 4 \mathrm{H}$, 6H, 15R, and 21R. Phys Rev 173:787-793

8. Muench WV, Pettenpaul E (1977) Saturated electron drift velocity in 6H silicon carbide. J Appl Phys 48:4823-4825

9. Arlt G, Schodder GR (1965) Some elastic constants of silicon carbide. J Acoust Soc Am 37:384-386

10. Ruddy FH, Dulloo AR, Seidel JG, Seshadri S, Rowland LB (1998) Development of a silicon carbide radiation detector. IEEE Trans Nucl Sci 45:536-541

11. Bertuccio G, Casiraghi R (2003) Study of silicon carbide for X-ray detection and spectroscopy. IEEE Trans Nucl Sci 50:175-185

12. Tan J, Meadows PJ, Zhang D, Chen X, López-Honorato E, Zhao X, Yang F, Abram T, Xiao P (2009) Young's modulus measurements of $\mathrm{SiC}$ coatings on spherical particles by using nanoindentation. J Nucl Mater 393:22-29

13. Xu J, Mei J, Rui Y, Chen D, Cen Z, Li W, Ma Z, Xu L, Huang X, Chen $K$ (2006) UV and blue light emission from SiC nanoclusters in annealed amorphous SiC alloys. J Non-Cryst Sol 352:1398-1401
14. Fan JY, Wu XL, Chu PK (2006) Low-dimensional SiC nanostructures: fabrication, luminescence, and electrical properties. Prog Mat Sci 51:983-1031

15. Wong EW, Sheehan PE, Lieber CM (1997) Nanobeam mechanics: elasticity, strength, and toughness of nanorods and nanotubes. Science 277:1971-1975

16. Anderson DA, Spear WE (1977) Electrical and optical properties of amorphous silicon carbide, silicon nitride and germanium carbide prepared by the glow discharge technique. Phil Mag 35:1-16

17. Jen TS, Pan JW, Shin NF, Tsay WC, Hong JW, Chang CY (1994) Hydrogenated amorphous silicon carbide $\mathrm{P}-\mathrm{I}-\mathrm{N}$ thin-film lightemitting diodes with barrier layers inserted at P-I interface. Jpn J Appl Phys 33:827-831

18. Ma T, Xu J, Du J, Li W, Huang X, Chen K (2000) Full color light emission from amorphous $\mathrm{SiCx}: \mathrm{H}$ with organic-inorganic structures. J Appl Phys 88:6408-6412

19. Fernandes $M$, Vieira M, Rodrigues I, Martins R (2004) Large area image sensing structures based on a-SiC:H: a dynamic characterization. Sens Actuators A Phys 113:360-364

20. Myong SY, Kim SS, Lim KS (2004) In situ ultraviolet treatment in an Ar ambient upon p-type hydrogenated amorphous siliconcarbide windows of hydrogenated amorphous silicon based solar cells. Appl Phys Lett 84:5416-5418

21. Akiyama M, Hanada M, Takao H, Sawada K, Ishida M (2002) Excess noise characteristics of hydrogenated amorphous silicon P-I-N photodiode films. Jpn J Appl Phys 41:2552-2555

22. Kortright JB, Windt DL (1988) Amorphous silicon carbide coatings for extreme ultraviolet optics. Appl Opt 27:2841-2846

23. Joung $\mathrm{YH}$, Kang HI, Kim JH, Lee HS, Lee J, Choi WS (2012) SiC formation for a solar cell passivation layer using an RF magnetron co-sputtering system. Nano Res lett 7:22

24. Shimada T, Katayama Y, Komatsubara KF (1979) Compositional and structural properties of amorphous $\mathrm{Si}_{x} \mathrm{C}_{1-x}: \mathrm{H}$ alloys prepared by reactive sputtering. J Appl Phys 50:5530-5532

25. Costa AK, Camargo SS Jr, Achete CA, Carius R (2000) Characterization of ultra-hard silicon carbide coatings deposited by RF magnetron sputtering. Thin Solid Films 377-378:243-248

26. Choi WK, Loo FL, Ling CH, Loh FC, Tan KL (1995) Structural and electrical studies of radio frequency sputtered hydrogenated amorphous silicon carbide films. J Appl Phys 78:7289-7294

27. Gupta A, Paramanik D, Varma S, Jacob C (2004) CVD growth and characterization of 3C-SiC thin films. Bull Mater Sci 27:445-451

28. Swain BP, Dusane RO (2007) Effect of substrate temperature on HWCVD deposited a-SiC:H film. Mater Lett 61:4731-4734

29. El Khakani MA, Chaker M, Jean A, Boily S, Pépin H, Kieffer JC, Gujrathi SC (1993) Effect of rapid thermal annealing on both the stress and the bonding states of a-SiC:H films. J Appl Phys 74:2834-2840

30. ElGazzar H, Abdel-Rahman E, Salem HG, Nassar F (2010) Preparation and characterizations of amorphous nanostructured $\mathrm{SiC}$ thin films by low energy pulsed laser deposition. Appl Surf Sci 256:2056-2060

31. Keffous A, Bourenane K, Kechouane M, Gabouze N, Kerdja T (2007) Morphological, structural and optical properties of thin $\mathrm{SiC}$ layer growth onto silicon by pulsed laser deposition. Vacuum 81:632-635

32. Katharria YS, Kumar S, Choudhary RJ, Prakash R, Singh F, Lalla NP, Phase DM, Kanjilal D (2008) Pulsed laser deposition of SiC thin films at medium substrate temperatures. Thin Solid Films 516:6083-6087

33. Chrisey DB, Hubler GK (2003) Pulsed laser deposition of thin films. Wiley-VCH, Hoboken

34. Lowndes DH, Geohegan DB, Puretzky AA, Norton DP, Rouleau CM (1996) Synthesis of novel thin-film materials by pulsed laser deposition. Science 273:898 
35. Venkatesan T, Wu XD, Inam A, Wachtman JB (1988) Observation of two distinct components during pulsed laser deposition of high Tc superconducting films. Appl Phys Lett 52:1193-1195

36. Gonzalo J, Afonso CN, Perrière J, Gómez San Roman R (1996) The importance of gas scattering processes on the stoichiometry deviations of laser deposited films. Appl Surf Sci 96:693-696

37. Acquaviva S, D'anna E, Giorgi MLD, Luches A (2003) Mass distribution in laser-produced plasma during ablation of complex targets. In: Gammino S, Mezzasalma AM, Neri F, Torrisi L (eds) Plasma production by laser ablation. World Scientific, Singapore, pp 64-71

38. Colomban P (2011) SiC, from amorphous to nanosized materials, the exemple of SiC fibres issued of polymer precursors. In: Mukherjee M (ed) Silicon carbide-materials, processing and applications in electronic devices. Intech, Rijeka, pp 169-185

39. Won Dong J, Ramirez MO, Kang H, Gopalan V, Baril NF, Calkins J, Badding JV, Sazio PJA (2007) All-optical modulation of laser light in amorphous silicon-filled microstructured optical fibers. Appl Phys Lett 91:1611111-1611113

40. Cheng $\mathrm{CH}$, Wu CL, Lin $\mathrm{YH}$, Yan WL, Shih MH, Chang JH, Wu Cl, Lee CK, Lin GR (2015) Strong optical nonlinearity of the nonstoichiometric silicon carbide. J Mater Chem C 3:10164-10176

41. Jin CG, Wu XM, Zhuge LJ (2008) Room-temperature growth of SiC thin films by dual-ion-beam sputtering deposition. Res Lett Phys Chem 2008:5

42. Dey PP, Khare A (2016) Effect of substrate temperature on structural and linear and nonlinear optical properties of nanostructured PLD a-SiC thin films. Mater Res Bull 84:105-117

43. Chu H, Gu C, Li S, Zhang Y, Bian J, Jiang C (2017) Measuring the absorption of TiN metallic films using cathodoluminescence of GaN films. Opt Mater Exp 7:1302-1309

44. Tauc J, Grigorovici R, Vancu A (1966) Optical properties and electronic structure of amorphous germanium. Phy Stat Sol B 15:627-637

45. Xanthakis JP (1993) Electronic structure and band-gap study of $\mathrm{Si}_{1-x} \mathrm{C}_{\mathrm{x}}$. J Non-Cryst Sol 164:1019-1022

46. Robertson J (1992) The electronic and atomic structure of hydrogenated amorphous Si-C alloys. Philos Mag B 66:615-638

47. Street RA, Nickel NH, Tsai CC (1995) Luminescence of a-Si:C:H alloys deposited with hydrogen dilution. J Non-Cryst Sol 190:33-37

48. Singh N, Kaur D (2016) Influence of sputtering power on structural, mechanical and photoluminescence properties of nanocrystalline SiC thin films. AIP Conf Proc 1728:020653
49. Wang J, Suendo V, Abramov A, Yu L, Roca-i-Cabarrocas P (2010) Strongly enhanced tunable photoluminescence in polymorphous silicon carbon thin films via excitation-transfer mechanism. Appl Phys Lett 97:221113

50. Coscia U, Ambrosone G, Basa DK (2008) Room temperature visible photoluminescence of silicon nanocrystallites embedded in amorphous silicon carbide matrix. J Appl Phys 103:0635071-0635076

51. Künle M, Kaltenbach T, Löper P, Hartel A, Janz S, Eibl O, Nickel KG (2010) Si-rich a-SiC:H thin films: structural and optical transformations during thermal annealing. Thin Solid Films 519:151-157

52. Cui J, Rusli, Yoon SF, Yu MB, Chew K, Ahn J, Zhang Q, Teo EJ, Osipowicz T, Watt $F$ (2001) Effects of microwave power on the structural and emission properties of hydrogenated amorphous silicon carbide deposited by electron cyclotron resonance chemical vapor deposition. J Appl Phys 89:2699-2705

53. Siebert W, Carius R, Fuhs W, Jahn K (1987) Photoluminescence in a-Si ${ }_{1-x} C_{x}: H$ films. Phys Stat Sol B 140:311-321

54. Chew K, Rusli Yoon SF, Ahn J, Ligatchev V, Teo EJ, Osipowicz T, Watt F (2002) Hydrogenated amorphous silicon carbide deposition using electron cyclotron resonance chemical vapor deposition under high microwave power and strong hydrogen dilution. J Appl Phys 92:2937

55. Wakita K, Makimura S, Nakayama Y (1995) Effect of annealing on photoluminescence spectra and film structure in a-SiN $\mathrm{S}_{\mathrm{x}}: \mathrm{H}$. Jpn J Appl Phys 34:1425-1430

56. Wang M, Xie M, Ferraioli L, Yuan Z, Li D, Yang D, Pavesi L (2008) Light emission properties and mechanism of low-temperature prepared amorphous $\mathrm{SiN}_{\mathrm{x}}$ films. I. Room-temperature band tail states photoluminescence. J Appl Phys 104:0835041-0835044

57. Street RA (1981) Luminescence and recombination in hydrogenated amorphous silicon. Adv Phys 30:593-676

58. Tsang C, Street RA (1979) Recombination in plasma-deposited amorphous Si:H. Luminescence decay. Phys Rev B 19:3027-3040

59. Street RA (1978) Phonon interactions in the luminescence of amorphous silicon. Philos Mag B 37:35-42

Publisher's Note Springer Nature remains neutral with regard to jurisdictional claims in published maps and institutional affiliations. 